\title{
Harlequin Syndrome: A new observation after thyroidectomy.
}

\author{
Deepak Rajput ${ }^{1}$, Gopalakrishnan $\mathrm{G}^{2}$, Debasis Naik ${ }^{2}$, Gaind Kumar ${ }^{2}$ \\ ${ }^{I}$ (Senior Resident, Department of Surgery, V.M.M.C. and Safdarjung Hospital, New Delhi, India.) \\ ${ }_{2}^{2}$ (Post-Graduate, Department of Surgery, V.M.M.C. and Safdarjung Hospital, New Delhi, India.)
}

\begin{abstract}
Harlequin syndrome is caused by autonomic dysfunction, affecting sweating and flushing of the face and less commonly, the upper limb and upper chest. It results from compromise of vasomotor and pseudomotor sympathetic nerve supply to one side of face with over-reaction, presumably compensatory, of the corresponding fibres on the intact side. This syndrome is a rare phenomenon, and is even rare following thyroidectomy, but is a worrying symptom for both the patient and the surgeon. Till now only a single case of Harlequin syndrome has been reported following thyroidectomy, we hereby present the second case of Harlequin syndrome following thyroidectomy, in a 40 year old female.
\end{abstract}

Keywords: Autonomic dysfunction, Harlequin sign, Harlequin syndrome, Sympathectomy, Thyroidectomy.

\section{Introduction}

Harlequin syndrome is caused by autonomic dysfunction, affecting sweating and flushing of the face and less commonly, the upper limb and upper chest[1]. It is considered a benign, idiopathic condition causing failure of the upper thoracic sympathetic chain with sparing of the first (oculomotor) thoracic segment, where in hard physical working situations are the precipitants[2]. Till now only a single case of Harlequin syndrome has been reported following thyroidectomy[3], we hereby present the second case of Harlequin syndrome following thyroidectomy.

\section{Case Report}

A 40 year old female with no comorbid illness or significant past history presented with a swelling in front of neck for last 24 months. On Examination, pulse - 84/ min, regular, B.P.- 110/74 mm Hg, with no signs of hypo/ hyperthyroidism. On Examination of neck, a firm, non-tender, $7.5 \times 4 \mathrm{~cm}$ swelling was noted in the thyroid region on the left side. Surface was smooth and the margins were well defined. USG neck revealed diffuse enlargement of left lobe of thyroid, $7.2 \times 3.8 \times 2 \mathrm{~cm}$ with normal right lobe. FNAC revealed Colloid goitre. Her routine laboratory investigations (Complete haemogram, Serum electrolytes, Renal function tests, Liver function tests, Random Blood sugar) were within normal limit. Her thyroid profile (TSH, FreeT 3 , FreeT 4 ) was also within the normal range. Patient underwent Left hemithyroidectomy which was uneventful. Patient was shifted to the ward after 4 hours of observation in the recovery room.

After 30 minutes, a call was received from the junior doctor on duty, for the patient developing flushing and sweating of left side of face. Patient was immediately attended, her vitals were normal, and a diagnosis of Harlequin syndrome was made[Fig. 1]. Her flushing and sweating subsided in the next hour. Postoperative serum calcium and thyroid profile were within normal limit. Duplex ultrasound of carotid arteries and MRI brain, cervical spine and thorax were normal. During her stay in hospital she had no further similar episode of flushing and sweating and was discharged on the $4^{\text {th }}$ post-operative day with reassurance, after explaining the nature of the disease. Patient was followed up for 3 months which was uneventful.

\section{Discussion}

The Harlequin syndrome, first described by Lance et al. in 1988, represents an uncommon disorder of the sympathetic nervous system. It is characterised by unilateral diminished sweating and flushing of the facial skin in response to heat or exercise[4].

In recent literature, the terms Harlequin syndrome and Harlequin sign have been used interchangeably. However, it is preferable to reserve the term Harlequin syndrome for patients that show the paroxysmal signs of hemifacial flushing and sweating, without other neurological symptoms. The Harlequin sign can be used to denote flushing and sweating in patients that also exhibit other associated autonomic signs or syndromes, such as Horner's syndrome, Adie's syndrome and Ross Syndrome[5].Harlequin syndrome is also known to be associated with brain stem infarcts, superior mediastinal neurinoma, internal jugular vein catherisation and carotid artery dissection[6].

Harlequin syndrome results from compromise of vasomotor and pseudomotor sympathetic nerve supply to one side of face with over-reaction, presumably compensatory, of the corresponding fibres on the intact side[7]. In our case, the patient was operated by left hemithyroidectomy, however, flushing and sweating was noted on the left side proving that surgery was not the cause for this. 
Harlequin syndrome is due to the involvement of pre-ganglionic fibres responsible for the innervation of the vaso-motor reflexes of the face arising from upper thoracic branches at the level of T2, T3. The sympathetic outflow pathway originates from the hypothalamus (first order neurons) and synapses in the lateral horn of spinal cord (second order neurons). Pseudomotor and vasomotor fibres innervating the face leave the spinal cord with ventral roots T2, T3 and travel along the sympathetic chain to the superior cervical ganglion and synapse with third order neuron[Fig.2]. Oculosympathetic neurons originate at T1 and travel along the same pathway. On the basis of the pattern of involvement of the face and presence or absence of horner's syndrome, localisation of the site of the lesion can be performed[2].

W.I.M. Willaert et al proposed the diagnostic workup and management of Harlequin syndrome [Chart 1]. Clinical and neurological examinations, as well as provocation tests are basic requirements to objectify the extent of the autonomic dysfunction. Imaging techniques including CT/ MRI of brain, spinal cord as well as the carotid arteries and lung apex must be performed to exclude any structural underlying lesion. If a Harlequin syndrome cannot be explained by an organic cause, the patients concerns should be relieved by benign nature of the condition. Generally, there is no medical need for follow-up visit. If social embarrassment impairs the patients quality of life, a contralateral sympathectomy may be considered, although compensatory flushing and sweating of other parts of the body may occur[5].

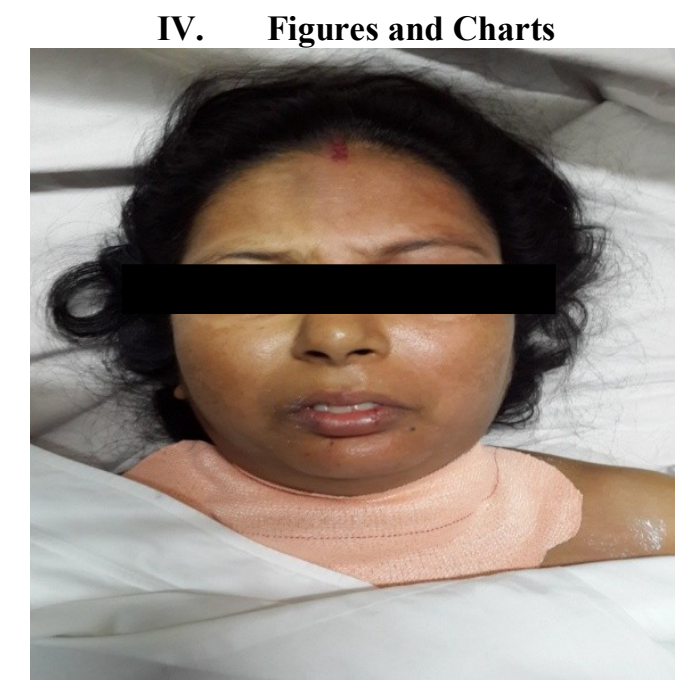

Fig. 1: Flushing of Left side of face (a presentation of Harlequin Syndrome)
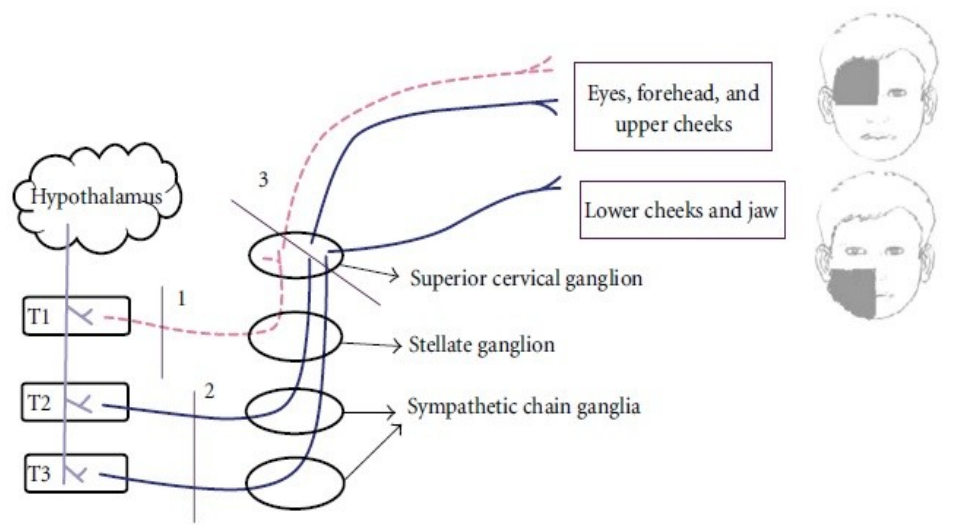

\footnotetext{
(1) Ocular findings in Horner's syndrome are associated with lesions at the level of T1 or anywhere along its path

(2) Sudomotor and vasomotor findings of Harlequin syndrome are secondary to the lesion at the levels, of $\mathrm{T} 2$ and $\mathrm{T} 3$ or anywhere along its path

(3) Lesion at superior cervical ganglion will lead to combined features of both Horner's and Harlequin syndrome

--- Pupillomotor fibres

- Vasomotor and sudomotor fibres
}

Fig. 2: Sympathetic innervation of face and clinical manifestations due to nerve injury. 


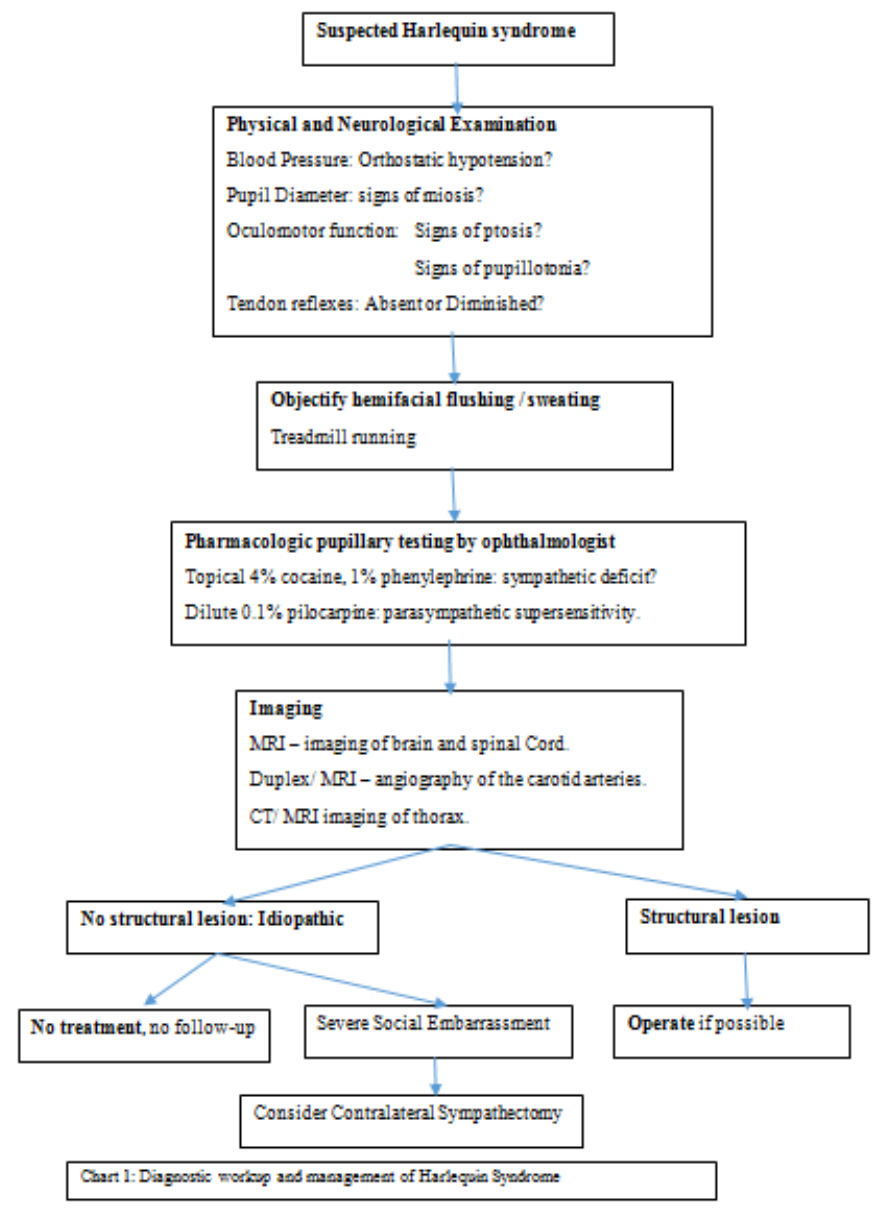

Chart 1: Diagnostic workup and management of Harlequin Syndrome

\section{Conclusion}

In conclusion, Harlequin syndrome is a rare phenomenon, and is even rare following thyroidectomy, but is a worrying symptom for both the patient and the surgeon. Though, most of the cases of Harlequin syndrome are of benign nature, it is necessary to have the knowledge about its nature, presentation and association by the attending surgeon or physician. Appropriate investigations should be done to rule out sinister causes.

\section{References}

[1] Shin RK, Galetta SL, Ting TY et al. Ross syndrome plus: beyond Horner, Holmes - Adie and harlequin. Neurology 2000; 55: 18416.

[2] E.M. Duddy and M.R. Baker, "Harlequin's darker side," The New England Journal of Medicine, Vol. 357, no. 20, p. e22, 2007.

[3] Van Slycke S, Stockman A, Dionigi G, Carette R, Gillardin JP, Brusselaers N. Harlequin syndrome after thyroidectomy for compressive retrosternal goiter. Case report and review of literature. Acta Chir Belg. 2014; 114(3): 212-4.

[4] Lance JW, Drummond PD, Gandevia SC, Morris JG. Harlequin syndrome: the sudden onset of unilateral flushing and sweating. J Neurol Neurosurg Psychiatry. 1988; 51: 635- 42.

[5] W.I.M. Willaert, M.R.M. Scheltinga, S.F. Steenhuisen and J.A.P. Hiel. Harlequin syndrome: two new cases and a management proposal. Acta Neurol. Belg. 2009; 109: 214-20.

[6] P.V. Pradeep, Ajith K. Benede, SkandhaS. Harshita, and B. Jayashree. Harlequin Syndrome in a case of Toxic goitre: A Rare Association. Case reports in Medicine. Volume 2011, Article ID 293076, 4 pages. doi: 10.1155/2011/293076.

[7] James W. Lance. Harlequin Syndrome. Practical Neurology. 2005; 5: 176 - 177 